\title{
Avaliação da qualidade microbiológica da água de propriedades leiteiras dos municípios de Campo Bonito, Cascavel e Guaraniaçú - PR
}

\author{
Microbiological quality assessment of water of dairy properties of \\ Campo Bonito, Cascavel, and Guaraniaçu - PR
}

\author{
Simone Cavalli Piana ${ }^{1}$; Samara Cavalli Piana²; Luciana Oliveira de Fariña ${ }^{3}$; \\ Fabiana André Falconit; Jardel José Busarello ${ }^{5}$
}

\begin{abstract}
Resumo
A água é considerada um dos elementos fundamentais para a existência do homem e precisa ser de qualidade. Porém, as condições gerais de saneamento deficientes são claramente refletidas nos dados disponíveis sobre mortalidade por doenças de veiculação hídrica. A cada ano, ocorrem cerca de 3,5 milhões de mortes relacionadas ao fornecimento inadequado de água, saneamento básico e higiene, predominantemente em países em desenvolvimento. O objetivo deste trabalho foi avaliar a qualidade da água utilizada na higienização do úbere das vacas, de equipamentos e utensílios de ordenha em propriedades leiteiras dos municípios de Campo Bonito, Cascavel e Guaraniaçú - PR. Para isso, foram coletadas 32 amostras de água, oriundas de poços e minas, não tratadas, no período de abril/2009 a abril/2010 e realizadas análises por meio da contagem do Número Mais Provável de coliformes totais e Escherichia coli, de acordo com o método de Colilert. Verificou-se que 93,75\% das amostras continham coliformes totais, que variaram de 2 a $\geq 2,4 \times 10^{3} \mathrm{NMP} / 100 \mathrm{~mL}$ e que $37,5 \%$ continham $E$. coli, que variaram de 2 a $170 \mathrm{NMP} / 100 \mathrm{~mL}$. A partir dos dados conclui-se que 37,5\% das amostras estavam em desacordo com o padrão estabelecido pela Portaria no 2914/2011 do Ministério da Saúde, que preconiza ausência de E.coli em $100 \mathrm{~mL}$ de água não tratada, proveniente de fontes e minas. Diante do contexto, propõe-se a realização de um trabalho de educação sanitária junto à população do meio rural, a adoção de medidas preventivas visando minimizar a ocorrência de enfermidades de veiculação hídrica, com a consequente melhoria da qualidade do leite produzido nessas propriedades. Palavras-chave: Qualidade da água. Leite. Zona rural.
\end{abstract}

\begin{abstract}
Water is considered a key element for the existence of man and needs to have a good quality. However, the general conditions of deficient sanitation are clearly reflected in the available data on mortality from waterborne diseases. The present study was aimed at evaluating the quality of the water used for the cleaning of dairy-cow teats and milking equipment on dairy farms located in the municipalities of Campo Bonito, Cascavel and Guaraniaçu, in Paraná State, Brazil. To do that, 32 samples of water, from of artesian well and sources, untreated, were taken from april/2009 through april/2010 end analysed by using the MPN (Most Probably Number) technique in the enumeration of total coliforms and E. coli, according to the Colilert method. Analysis showed that $93.75 \%$ contained total coliforms, that ranged
\end{abstract}

\footnotetext{
${ }^{1}$ Acadêmica do Curso de Medicina da Universidade Estadual do Oeste do Paraná (UNIOESTE)

${ }^{2}$ Acadêmico do Curso de Agronomia da Universidade Estadual de Maringá (UEM)

${ }^{3}$ Doutora em Ciências de Alimento. Professor da Universidade estadual do Oeste do Paraná - UNIOESTE.

${ }^{4}$ Doutora em Ciências de Alimento. Professor da Universidade estadual do Oeste do Paraná - UNIOESTE.

${ }^{5}$ Consultor em Agronegócios do Serviço de Apoio às Micro e Pequenas Empresas de São Paulo, Brasil
} 
from $2 \mathrm{MPN}$ to $\geq 2.4 .10^{3} \mathrm{MPN} / 100 \mathrm{~mL}$, and $37.5 \%$ contained $E$. coli, that ranged from $2 \mathrm{MPN}$ to 170 MPN/100 mL. It shows that $37.5 \%$ of the samples did not meet the requirements of the Brazilian Health Ministry regulation 518/2004. Within the context, the results indicate the need for a sanitary education effort involving the rural population, coupled with the implementation of preventive measures, in order to improve the quality of the milk produced in the facilities studied.

Keywords: Water quality. Milk. Rural areas.

\section{Introdução}

A água é considerada um dos elementos fundamentais para a existência do homem; suas funções no abastecimento público, industrial e agropecuário, na preservação da vida aquática, na recreação e no transporte demonstram essa importância vital (GUILHERME et. al., 2000). Porém, as condições gerais de saneamento deficientes observadas, sobretudo, nos países em desenvolvimento, são claramente refletidas nos dados disponíveis sobre mortalidade por doenças de veiculação hídrica. De acordo com a Organização Mundial da Saúde, 2,4 bilhões de pessoas não vivem em condições aceitáveis de saneamento e 1,1 bilhão de pessoas não têm acesso a um adequado abastecimento de água (WHO, 2010).

A ausência ou a precária proteção dos recursos hídricos pode introduzir na água uma série de organismos patogênicos, tais como vírus, bactérias, protozoários ou helmintos de origem intestinal, tornando-a um veículo de transmissão de doenças (SÁ et al., 2005). O risco de ocorrência de surtos de doenças de veiculação hídrica no meio rural é alto, principalmente em função da possibilidade de contaminação bacteriana de águas que muitas vezes são captadas em poços velhos, inadequadamente vedados e próximos de fontes de contaminação, como fossas e áreas de pastagem ocupadas por animais (AMARAL et al., 2003), condições oriundas da falta de estrutura sanitária desses locais e de informação por parte dos produtores. Assim sendo, a maioria das doenças nas áreas rurais poderia ser consideravelmente reduzida, desde que a população tivesse acesso à água potável (AMARAL et al., 2006).
A pecuária de leite é uma atividade de grande relevância em diversas regiões brasileiras, principalmente no Sul e Sudeste, tanto por ser um complemento na renda dos pequenos produtores quanto por se tratar de um produto de alto valor nutritivo, fonte de energia, proteínas, cálcio e fósforo. Portanto, em consequência de sua importância, o leite deve exercer sua função nutricional de uma forma segura, ou seja, isento de patógenos (COSTA, 2006).

Atualmente, o Brasil é o sexto maior produtor de leite do mundo e, nos últimos dez anos, houve um aumento considerável da produção. Apesar desta posição notável, a pecuária leiteira nacional, ao longo de sua história, tem sido marcada por sucessivas crises de ordem estrutural, administrativa e política. Para fazer frente a essas crises, a melhoria da qualidade da matéria-prima tem sido vista como uma importante estratégia capaz de garantir a sobrevivência e a competitividade do setor lácteo nacional, que está condicionada à garantia e melhoria da qualidade de seus produtos a custos de produção competitivos (SCALCO; TOLEDO, 2005; CARVALHO et al., 2010). Outra característica marcante da produção leiteira no Brasil é o predomínio de pequenas e médias propriedades com características de agricultura familiar. Assim, a falta de informação, assistência e investimentos na produção leiteira geram baixas produtividade e qualidade do produto (TKAEZ et al., 2004 apud CARVALHO et al., 2010).

O Estado do Paraná vem apresentando um expressivo crescimento da produção leiteira, a qual entre 1997 e 2006 foi de 71\%, consolidando-o como o segundo estado produtor de leite do Brasil. Esta expansão foi mais intensa nas regiões Oeste 
e Sudoeste do Estado, com forte crescimento do rebanho e dos níveis de produtividade (WIRBISKI et al., 2009 apud BUSARELLO et al., 2010).

Pode-se observar que a qualidade insatisfatória do leite produzido no Brasil é um problema crônico, de difícil solução, em que fatores de ordem social, econômica, cultural e climática estão envolvidos (GUIMARÃES, 2002). Trabalhos desenvolvidos em diferentes regiões do país têm revelado grande percentual de amostras de leite fora dos padrões estabelecidos pela legislação vigente para contagem de micro-organismos. Diante disso, tem-se buscado encontrar quais são os fatores que estão interferindo na qualidade do leite para que ela possa ser aprimorada.

A qualidade do leite é amplamente estudada e depende de fatores como saúde do animal, produtor, assepsia do úbere, higienização dos equipamentos de ordenha, tanque resfriador e qualidade da água. Os diversos pesquisadores que têm se dedicado a estudar o assunto acreditam que a qualidade da água utilizada para lavagem dos utensílios, equipamentos de ordenha e tetas dos animais é fundamental para evitar a contaminação do leite e veicular microorganismos para a glândula mamária (POLEGATO; AMARAL, 2005; AMARAL et al., 2006; COSTA, 2006; BIANCONI et al., 2007; JATOBÁ, 2009; SANTOS; FONSECA, 2009).

Nesse sentido, Cerqueira et. al. (2006) relataram em seu trabalho que se a água utilizada para obtenção do leite for de baixa qualidade, além de aumentar a contagem bacteriana total do leite, poderá veicular patógenos de importância em saúde pública. Também, segundo Polegato e Amaral (2005), a água tem grande importância na cadeia produtiva do leite e, assim sendo, deve ser de qualidade já na sua origem ou por meio de algum tratamento para utilização na pecuária leiteira.

Soma-se a isso o fato de que a água é o principal ingrediente empregado na limpeza e desinfecção e que sua qualidade tem impacto direto na eficiência desses processos, podendo vir a ser uma via de transmissão de doenças e contribuir para a diminuição da vida útil do equipamento. Considerando que o equipamento de ordenha é uma fonte importante de contaminação do leite, os procedimentos de limpeza e higienização irão influenciar diretamente no seu nível de qualidade microbiológica. Entre as causas mais comuns de problemas ligados à limpeza de equipamentos de ordenha destaca-se o uso de temperatura abaixo do recomendado, baixa concentração de detergentes e qualidade insatisfatória da água (SANTOS; FONSECA, 2009).

A Instrução Normativa 51/2002 do Ministério da Agricultura, Pecuária e Abastecimento (BRASIL, 2002) dispõe sobre a produção, identidade e qualidade de leite, regulamentando que as instalações devem ser mantidas sob condições adequadas de limpeza e higiene, tendo ponto de água corrente de boa qualidade para lavagem de latões e de utensílios de coleta e que a qualidade microbiológica da água utilizada na limpeza e sanitização constitui ponto crítico no processo de obtenção e refrigeração do leite. Ainda estabelece que a fonte de abastecimento de água deva assegurar um volume compatível com a produção, devendo ser de boa qualidade e apresentar, obrigatoriamente, característica de potabilidade.

A Portaria 2914/2011 do Ministério da Saúde (BRASIL, 2011) estabelece a qualidade da água para consumo humano, regulamentando que deve possuir ausência de Escherichia coli e/ou coliformes termotolerantes em $100 \mathrm{~mL}$ de amostra, sendo que em amostras individuais procedentes de formas de abastecimento sem distribuição canalizada tolera-se a presença de coliformes totais; nessa situação deve ser investigada a origem da ocorrência, tomadas providências imediatas de caráter corretivo e preventivo e realizada nova análise.

Enfatizando a importância da água no consumo e na produção leiteira, realizou-se este estudo objetivando avaliar a qualidade da água utilizada na higienização do úbere dos animais, equipamentos 
e utensílios de ordenha em propriedades leiteiras familiares dos municípios de Campo Bonito, Cascavel e Guaraniaçú, PR.

\section{Metodologia}

Para determinação da qualidade da água foram selecionadas 32 pequenas propriedades produtoras de leite, localizadas nos municípios de Campo Bonito, Cascavel e Guaraniaçú, Estado do Paraná, durante o período de abril de 2009 a abril de 2010. As amostras de água utilizadas para lavagem de equipamentos e utensílios de ordenha foram coletadas de poços artesianos, minas, rios e fontes, sendo todas não tratadas. A coleta das amostras foi realizada assepticamente em frascos estéreis e, a seguir, estas foram transportadas, sob refrigeração, ao Laboratório de Controle Microbiológico de Água, Alimentos e Medicamentos da Universidade Estadual do Oeste do Paraná (UNIOESTE), para análise de sua qualidade microbiológica.

Realizou-se a contagem de coliformes totais e fecais, utilizando-se a metodologia Colilert (AMERICAN PUBLIC HEALTH ASSOCIATION, APHA, 2005). Foi adicionado o reagente cromogênico Colilert $\AA$, que contem os substratos ONPG e MUG (o-nitrofenil- $\beta$-galactosideo e 4-metilumbeliferil- $\beta$-D-glucuronideo) em $100 \mathrm{~mL}$ de água. A seguir, a amostra foi homogeneizada e adicionada em Cartela Quanti-tray ${ }^{\circledR}$, que foi selada e incubada em estufa microbiológica a $36^{\circ} \mathrm{C}$ durante 24 horas.

À medida que os coliformes se reproduzem no Colilert, eles utilizam a enzima $\beta$-galactosidase para metabolizar o indicador de nutriente ONPG e alterá-lo de incolor para amarelo, pela produção de o-nitrofenol. Já, E. coli produz a enzima $ß$-glucuronidase que metaboliza o substrato MUG em 4-metil-umbeliferona, que apresenta fluorescência na luz UV.

Posteriormente, procedeu-se a leitura, onde as cavidades amarelas indicavam a presença de coliformes totais e as amarelas, com fluorescência na luz UV, indicavam a presença de E. coli. O resultado foi expresso em Número Mais Provável (NMP) de coliformes totais e fecais/100 mL de água, utilizandose a tabela específica que acompanha o reagente.

Os resultados foram transcritos em laudos, que avaliavam a qualidade da água para o consumo humano, conforme a Portaria 2914/2011 do Ministério da Saúde e encaminhados aos produtores para que pudessem tomar providências.

\section{Resultados e Discussão}

Os resultados das contagens de coliformes totais e E. coli para 32 amostras de água, coletadas nos municípios de Campo Bonito, Cascavel e Guaraniaçú - PR, encontram-se na Tabela 1. 
Tabela 1: Contagem de coliformes totais e E. coli presentes nas amostras de água de 32 propriedades leiteiras dos municípios de Campo Bonito, Cascavel e Guaraniaçú - PR.

\begin{tabular}{|c|c|c|}
\hline Amostra & $\begin{array}{l}\text { Coliformes totais } \\
\text { (NMP } / 100 \mathrm{~mL} \text { ) }\end{array}$ & $\begin{array}{c}\text { E. coli } \\
(\mathrm{NMP} / 100 \mathrm{~mL})\end{array}$ \\
\hline 01 & $9,0 \times 10^{2}$ & $<2,0$ \\
\hline 02 & $1,6 \times 10^{3}$ & 8,0 \\
\hline 03 & $1,3 \times 10^{2}$ & 8,0 \\
\hline 04 & $\geq 2,4 \times 10^{3}$ & 2,0 \\
\hline 05 & $7,0 \times 10^{2}$ & $<2,0$ \\
\hline 06 & $1,3 \times 10^{2}$ & $<2,0$ \\
\hline 07 & 7,0 & $<2,0$ \\
\hline 08 & 7,0 & $<2,0$ \\
\hline 09 & $<2,0$ & $<2,0$ \\
\hline 10 & 7,0 & 4,0 \\
\hline 11 & $2,4 \times 10^{2}$ & $<2,0$ \\
\hline 12 & $1,4 \times 10$ & $<2,0$ \\
\hline 13 & $3,0 \times 10$ & 4,0 \\
\hline 14 & $3,3 \times 10$ & $<2,0$ \\
\hline 15 & $6,3 \times 10$ & $<2,0$ \\
\hline 16 & 2,0 & $<2,0$ \\
\hline 17 & $1,1 \times 10$ & $<2,0$ \\
\hline 18 & 5,0 & $<2,0$ \\
\hline 19 & $1,1 \times 10^{2}$ & 4,0 \\
\hline 20 & $1,7 \times 10^{2}$ & $<2,0$ \\
\hline 21 & $1,7 \times 10^{2}$ & $1,7 \times 10^{2}$ \\
\hline 22 & $2,2 \times 10$ & $<2,0$ \\
\hline 23 & $3,0 \times 10$ & 2,0 \\
\hline 24 & $3,0 \times 10^{2}$ & $<2,0$ \\
\hline 25 & 4,0 & $<2,0$ \\
\hline 26 & $1,4 \times 10$ & 4,0 \\
\hline 27 & $3,4 \times 10$ & $2,2 \times 10$ \\
\hline 28 & $<2,0$ & $<2,0$ \\
\hline 29 & $<2,0$ & $<2,0$ \\
\hline 30 & $\geq 2,4 \times 10^{3}$ & $2,6 \times 10$ \\
\hline 31 & $\geq 2,4 \times 10^{3}$ & $2,7 \times 10$ \\
\hline 32 & 8,0 & $<2,0$ \\
\hline
\end{tabular}

Na tabela 1, pode-se observar que 93,75\% (29) das amostras apresentavam presença de coliformes totais, que variaram de $2 \mathrm{a} \geq 2,4 \times 10^{3} \mathrm{NMP} / 100 \mathrm{~mL}$ e que $37,5 \%$ (12) apresentaram $E$. coli, que variaram de 2 a 170 NMP/100 mL. Assim sendo, observa-se que $37,5 \%$ das amostras estavam em desacordo com o padrão estabelecido pela Portaria $n^{\circ}$ 2914/2011 do Ministério da Saúde, que preconiza ausência de E. coli e/ou coliformes termotolerantes em 100 $\mathrm{mL}$ de água. Essa mesma portaria regulamenta que em amostras individuais procedentes de poços, fontes, nascentes e outras formas de abastecimento sem distribuição canalizada toleram-se a presença de coliformes totais, na ausência de E.coli e/ ou coliformes termotolerantes. Entretanto, nessa situação deve ser investigada a origem da ocorrência, tomadas providências imediatas de caráter corretivo e preventivo e realizada nova análise, situação em que se enquadra grande parte das amostras de água analisadas.

Esses valores são preocupantes, tendo em vista que a água não sofre nenhum tratamento nas propriedades antes de ser utilizada a nível doméstico ou na produção ou no processamento do leite.

Segundo Cerqueira et al. (2006), a negligência no controle de qualidade da água tem contribuído para a ocorrência de problemas que vão desde a transmissão de doenças ao homem e aos animais, até perdas econômicas devido à elevação da contagem bacteriana total do leite e do tanque e pela maior taxa de mastite no rebanho (SANTOS; FONSECA, 2007). Fonseca e Santos (2000) apud Concianini (2006) consideram que mais de $95 \%$ das causas de alta contagem microbiológica no leite sejam originárias de falhas na lavagem e higienização dos utensílios e equipamentos de ordenha.

Lacerda et al. (2009) avaliaram a qualidade da água utilizada em propriedades leiteiras de três municípios do Estado do Maranhão e encontraram $90 \%$ das amostras contaminadas por coliformes totais e $75 \%$ por E. coli. Os autores sugeriram que as altas contagens de coliformes encontradas na água das propriedades foram devido à disposição inadequada de resíduos orgânicos oriundos de atividades humana e animal, aliado à ausência de limpeza das caixas d'água e de tratamento químico da água, bem como pelo desconhecimento do produtor rural em relação ao risco à saúde decorrente do uso e do consumo de águas contaminadas.

$\mathrm{Na}$ região de Cerqueira César - SP, Medeiros e Souza (2009), ao acompanharem 16 propriedades rurais leiteiras, verificaram que $57 \%$ das águas utilizadas nas propriedades advinham de minas, $31 \%$ de poços, $6 \%$ eram tratadas e $6 \%$ de rio e, na análise dessas fontes, verificaram que $56 \%$ das amostras estavam fora dos padrões de potabilidade. 
Quanto à água disponível no local de ordenha proveniente de torneiras - em $51 \%$ foi isolada $E$. coli, sugerindo-se que os produtores não cuidavam da manutenção de suas caixas d'água, tornando-as possíveis veículos de transmissão de enfermidades.

Também Ribeiro et al. (2000) estudaram 45 propriedades produtoras de leite localizadas nos estados de São Paulo e Minas Gerais, verificando que $75,55 \%$ delas apresentavam contagem de coliformes totais, enquanto $E$. coli foi identificada em $20 \%$ das amostras. Os autores ressaltaram que a utilização de água de boa qualidade para o preparo dos animais para a ordenha e para a limpeza dos equipamentos é essencial para contribuir com a qualidade do leite e com a prevenção de mastite, uma vez que alguns patógenos causadores dessa infecção podem ser transmitidos pela água.

Ao estudar propriedades leiteiras de Minas Gerais, Picinin (2003) observou que, das propriedades que possuíam como origem da água mina, cisterna, ou riacho, $100 \%$ apresentaram amostras não potáveis e, das que possuíam poço ou rede de distribuição, apenas $42,86 \%$ apresentaram água potável. De forma semelhante, Rapini et al. (2010), ao avaliar a qualidade microbiológica da água de 49 propriedades leiteiras situadas na região metropolitana de Belo Horizonte - MG, observaram que $79,6 \%$ das amostras analisadas apresentaram coliformes totais e $69,4 \%$ E. coli, mostrando a qualidade insatisfatória das mesmas.

Em Maringá - PR, Nogueira et al. (2003) analisaram a água de consumo humano não clorada proveniente de comunidades urbanas e rurais e verificaram que $83 \%$ das amostras encontravam-se contaminadas por coliformes totais e $48 \%$ por $E$. coli. Já Ramires et al. (2009), ao analisar a qualidade da água e do leite de 162 propriedades na região dos Campos Gerais - PR, observaram que apenas 38\% delas apresentaram água potável. O estudo, porém, não encontrou valores significativos de correlação entre a qualidade microbiológica da água e a do leite, sugerindo então que altos valores de contagem de células somáticas e contagem bacteriana total do leite ocorreram por falhas na higienização no processo de obtenção do leite e dos equipamentos das propriedades.

Lima (2007), em seu trabalho, estudou a produção leiteira de 180 produtores da Zona da Mata - MG, observando que a principal fonte de água foi a captada em minas $(67 \%)$ e que $21 \%$ dos produtores utilizavam água proveniente de fontes abertas, revelando como a água captada para as operações de higienização e sanificação poderia estar contaminada. A autora sugeriu, ao final da pesquisa, que esse pode ser um dos fatores responsáveis pelo resultado da elevada contaminação das amostras de leite estudadas no mesmo trabalho. Costa (2006) também acompanhou propriedades familiares produtoras de leite e verificou que $100 \%$ das amostras de água analisada estavam em desacordo com o padrão de potabilidade exigido.

Dados alarmantes também foram levantados por Polegato e Amaral (2005) que, ao realizarem inquérito junto a produtores de leite do município de Marília -SP, observaram que das 20 propriedades acompanhadas, $90 \%$ não efetuavam tratamento químico da água e os $10 \%$ que a tratavam o faziam de maneira inadequada, sendo que nenhuma delas havia analisado a qualidade da água anteriormente. Também observou que $40 \%$ das propriedades não possuíam água no local da ordenha e os cuidados higiênicos para obtenção do leite deixavam a desejar na maioria delas. Isso mostra como o conhecimento existente sobre a importância da qualidade da água na produção leiteira ainda não chegou para muitos e como há necessidade urgente de conscientizar os produtores - por meio de programas de educação em saúde - sobre como melhorar a qualidade da água utilizada na propriedade.

Em uma grande variedade de estudos que acompanharam pequenas propriedades leiteiras foi observado que as propriedades não adotavam as principais práticas de manejo higiênico-sanitário e controle da qualidade da água. Isso foi relatado 
pela ausência de fatores de proteção das fontes, da realização de limpeza e desinfecção dos reservatórios, bem como de tratamento, em que se pese a aversão dos residentes ao processo de cloração por questões sensoriais (MONTEIRO et. al., 2007; MARCÍLIO, 2008; LIMA, 2007; BARCELLOS et. al., 2006; COSTA, 2006). É interessante observar como a maioria dos proprietários considerava a água como sendo de boa qualidade, mesmo sem nunca ter feito sequer uma análise. Tal quadro, segundo Costa (2006), parece refletir a situação da grande maioria das propriedades rurais familiares do país, onde os moradores da área rural têm dificuldade no entendimento de algo que não possa passar pelos sentidos - como a presença de bactérias na água, por exemplo - principalmente naquelas águas com características estéticas límpidas, o que dificulta a mudança de comportamento em relação a elas.

Em relação às condições encontradas nas propriedades acompanhadas por este estudo, observou-se grande semelhança entre os diferentes municípios, nos quais os produtores utilizava os recursos hídricos disponíveis no local, provenientes de minas, fontes, córregos, rios, açudes e poços, sendo que nenhuma propriedade apresentava acesso à rede pública de abastecimento. Pôde-se observar também que muitas fontes estavam desprotegidas e/ou localizadas em locais não adequados, até mesmo em processo de degradação, necessitando urgentemente de auxílio para que pudessem ser recuperadas. Quanto aos resíduos produzidos pelas moradias, seu destino também demonstrou ser inadequado, pois não havia esgoto nem coleta do lixo.

Nas propriedades acompanhadas por este estudo, as práticas de higienização eram realizadas de forma ineficiente e tecnicamente incorreta pela maioria dos produtores. Em relação às propriedades leiteiras do município de Campo Bonito, Busarello et al. (2010) realizaram um estudo acompanhando um grande número delas e verificou que, apesar de 93\% dos produtores entrevistados considerarem a água utilizada de boa qualidade, $83 \%$ deles nunca haviam realizado análise de sua qualidade, sendo que $35 \%$ dos entrevistados afirmaram nunca ter feito desinfecção dos reservatórios em suas propriedades. De forma similar a outras pesquisas, os dados encontrados corroboram a afirmação de que a realidade higiênicosanitária do meio rural é preocupante e necessita de atenção e cuidados especiais.

Tendo em vista todo o contexto, percebe-se como a prevenção da contaminação das águas é uma necessidade universal que exige atenção por parte das autoridades sanitárias e órgãos de saneamento, impondo-se exames rotineiros das mesmas com a avaliação do ponto de vista bacteriológico (GUILHERME et al., 2000). Entretanto, um dos maiores problemas das fontes particulares é a ausência de monitoramento da qualidade da água consumida (AMARAL, 2006).

Trabalhos de educação sanitária visando à preservação das fontes de água, o tratamento das águas e o tratamento de dejetos foram apontados como ferramentas necessárias para a redução do risco de veiculação de doenças pela água (AMARAL, 2003). Quanto a esta atividade, a Portaria 2914/11 do MS regulamenta que é dever e obrigação das Secretarias Municipais de Saúde exercer a vigilância da qualidade da água em sua área de competência e avaliar, sistemática e permanentemente, o risco à saúde humana de tais águas.

Os estudos corroboram a situação encontrada no presente trabalho acerca da necessidade de conhecimentos da realidade sanitária no meio rural, caracterizada por populações com menor acesso às medidas de saneamento e pela presença de atividades agropecuárias altamente impactantes.

\section{Conclusão}

Por meio da realização desta pesquisa, pôde-se observar que $37,5 \%$ da água utilizada na higienização do úbere dos animais, equipamentos e utensílios de ordenha nas propriedades leiteiras avaliadas não 
estavam enquadradas no padrão microbiológico para potabilidade exigido pela Portaria n ${ }^{\circ} 2914 / 2011$ do Ministério da Saúde, podendo assim vir a ser um veículo de contaminação microbiana do leite. Com relação ao fato de que $93,75 \%$ das amostras de água encontravam-se contaminadas por coliformes totais, observa-se que é necessário o acompanhamento da qualidade da água utilizada nestas propriedades, conforme orientações desta mesma portaria.

Com base nesses dados, pontua-se a necessidade da existência de um trabalho interativo de promoção da saúde junto à população do meio rural, instruindo-a sobre a importância da qualidade da água utilizada na propriedade, a adoção de medidas para protegê-la e o tratamento das águas comprometidas, visando minimizar a ocorrência de enfermidades de veiculação hídrica e a melhoria da qualidade do leite produzido nas propriedades.

\section{Agradecimentos}

À Fundação Araucária pelo apoio à pesquisa.

\section{Referências}

AMARAL, L. A.; FILHO, A. N; JÚNIOR, O. D. R; FERREIRA, F.; BARROS, L. S. S. Água de consumo humano como fator de risco à saúde em propriedades rurais. Revista Saúde Pública, São Paulo, v. 37, n.4, p.510-514, 2003.

AMARAL, L. A.; JÚNIOR, O. D. R.; FILHO, A. N.; BARROS, L. S. S.; SILVARES, P. M. Água utilizada em propriedades rurais para consumo humano e na produção de leite como veículo de bactérias do gênero Aeromonas. Revista Portuguesa de Ciências Veterinárias, Lisboa, v. 101, n. 557-558, p.103-107, 2006.

APHA, 2005. Standard Methods for the Examination of Water and Wastewater 21 st ed. American Public Health Association, Washington, D.C.
BARCELLOS, C. M.; ROCHA, M.; RODRIGUES, L. S.; COSTA, C. C.; OLIVEIRA, P. R.; SILVA, I. J.; JESUS, E. F. M.; ROLIM, R. G. Avaliação da qualidade da água e percepção higiênico-sanitária na área rural de Lavras, Minas Gerais, Brasil, 1999-2000. Caderno Saúde Pública, Rio de Janeiro, v. 22, n. 9, p. 967-1978, 2006.

BIANCONI, L.L.; GAMEIRO, A.H.; SAES, M.S.M. Um modelo de gestão e avaliação de procedimentos operacionais na pecuária leiteira. Anais. XLV Congresso da Sociedade Brasileira de Economia, Administração e Sociologia Rural. CD-ROM. Londrina: SOBER, 2007.

BRASIL. Ministério da Saúde. Secretaria Nacional de Vigilância Sanitária. Portarian 2.914 de 12 de dezembro de 2011. Dispõe sobre os procedimentos de controle e de vigilância da qualidade da água para consumo humano e seu padrão de potabilidade. Diário Oficial da União de 16/12/2011, Seção 1, pág. 266, 2011.

BRASIL. Ministério da Agricultura, Pecuária e do Abastecimento. Instrução Normativa n. 51 de 18 de setembro de 2002. Regulamento Técnico da Produção, Identidade e Qualidade do Leite Tipo C. Diário Oficial da União, Brasília, DF, 20 set. 2002. Seção 1, p. 13-22.

BUSARELLO, J. J.; FARIÑA, L. O.; BULHÕES, R.; FALCONI, F. A. Caracterização socioeconômica da atividade leiteira na micro-região do Piquiriguaçu no estado do Paraná. Programa de Gestão Tecnológica Empresarial da Unidade de Laticínio da Cooperativa de Leite da Agricultura Familiar com Interação Solidária de Campo Bonito-PR; 2010. Disponível em: $<$ http://cacphp.unioeste.br/projetos/cmetloeste/pub tecnicas/5_ATIVIDADE_LEITEIRA_NA_MICRO_ REGIAO_DO_PIQUIRIGUACU_NO.PDF>. Acesso em: 06 jun. 2010.

CARVALHO, D. SANTOS, A. C.; ALENCAR, E. Discrepâncias entre a Instrução Normativa $n^{\circ} 51$ e as ações e percepções dos agentes da produção primária em relação à qualidade do leite. Disponível em: $<\mathrm{http}: / /$ www.sober.org.br/palestra/12/02P137.pdf>. Acesso em: 06 jun. 2010. 
CERQUEIRA, M. M. O.; PICININ, L. C. A.; FONSECA, L. M; et al. Qualidade da água e seu impacto na qualidade microbiológica do leite. In: Congresso Brasileiro de Qualidade do Leite, 2., 2006, Goiânia. Anais... Goiânia: Conselho Brasileiro de Qualidade do Leite, 2006. p. 273-289

CONCIANINI, D. M. Avaliação do leite pasteurizado tipo C no Estado de Mato Grosso do Sul - Campo Grande. 2006. Dissertação (Mestre em Produção e Gestão Agroindustrial). Universidade para o Desenvolvimento do Estado e da Região do Pantanal UNIDERP, Campo Grande.

COSTA, F. F. Interferência de práticas de manejo na qualidade microbiológica do leite produzido em propriedades rurais familiares. 2006. Dissertação (Mestrado em Zootecnia). Universidade Estadual Paulista, Jaboticabal.

GUILHERME, E.F.M.; SILVA, J.A.M.; OTTO, S.S. Pseudomonas aeruginosa como indicador de contaminação hídrica. Revista Higiene Alimentar, São Paulo, v.14, n.76, p.43- 46, 2000.

GUIMARÃES, R. Importância da matéria-prima para a qualidade do leite fluido de consumo. Revista Higiene Alimentar, São Paulo, v.16, n. 102-103, p. 25-34, 2002.

JATOBÁ, R. B. Estabelecimento de uma curva de calibração para o equipamento bactcount para monitoramento da qualidade do leite cru refrigerado. 2009. Dissertação (Mestrado em Zootecnia) Universidade Federal Rural de Pernambuco, Recife.

LACERDA, L.M.; MOTA, R.A.; SENA, M. J. Qualidade microbiológica da água utilizada em fazendas leiteiras para limpeza das tetas de vacas e equipamentos leiteiros em três municípios do Estado do Maranhão. Arquivos do Instituto Biológico, São Paulo, v.76, n.4, p.569-575, 2009.

LIMA, L. L.; Características da produção e qualidade do leite cru na zona da mata de Minas Gerais, 2007. 2007. Dissertação (Mestrado em Medicina Veterinária - área de Tecnologia e Inspeção de Produtos de Origem Animal). Universidade Federal de Minas Gerais, Belo Horizonte.
MARCÍLIO, T. Qualidade do leite. 2008. Monografia (Trabalho de conclusão de curso de Especialização em Higiene e Inspeção de Produtos de Origem Animal). Universidade Castelo Branco. Florianópolis.

MEDEIROS, M. I. M.; SOUZA, L. C. Associação de agentes patogênicos isolados em análise microbiológica da água, com a presença de mastite clínica ou subclínica, em vacas de propriedades leiteiras da região de Cerqueira César - SP. Ciências Agrotécnica, Lavras, v. 33, n. 2, p. 580-585, 2009.

MONTEIRO, A.A.; TAMANINI, R.; da SILVA, L. C. C.; de MATTOS, M. R.; MAGNANI, D.F.; D’OVIDIO, L.; NERO, L. A.; BARROS, M. A. F.; PIRES, E.M.F.; PAQUEREAU, B. P. D.; BELOTI, V. Características da produção leiteira da região do agreste do estado de Pernambuco, Brasil. Semina: Ciências Agrárias, Londrina, v. 28, n. 4, p. 665-674, 2007.

NOGUEIRA, G.; NAKAMURA, C.V.; TOGNIM, M.C.B.; ABREU FILHO, B.A.; DIAS FILHO, B.P. Microbiological quality of drinking water of urban and rural communities, Brazil. Revista de Saúde Pública, São Paulo, v. 37, n.2, p. 232-236, 2003.

PICININ, L.C. A Qualidade do leite e da água de algumas propriedades leiteiras de Minas Gerais: 2003. $89 \mathrm{f}$. Dissertação (Mestrado) - Universidade de Minas Gerais, Belo Horizonte, 2003.

POLEGATO, E. P. S.; AMARAL, L. A. A qualidade da água na cadeia produtiva do leite: Nível de conhecimento do produtor rural. Revista Higiene Alimentar, São Paulo, v. 19, n. 129, p.15-24, 2005.

RAMIRES, C.H.; BERGER, E.L.;ALMEIDA, R. Influência da qualidade microbiológica da água sobre a qualidade do leite. Archives of Veterinary Science, Curitiba, v.14, n.1, p.36-42, 2009.

RAPINI, L.S.; CERQUEIRA, M.M.O.P.; SOUZA, R.M.B.; SOUZA, M.R.; PENNA, C.F.A.M. Avaliação da qualidade microbiológica da água de propriedades leiteiras: resultados parcias. Disponível em: $<\mathrm{http}$ ://www. vet.ufmg.br/academicos/pesquisa-napq/iniciacao-cientifica/ resumos-iniciacao-cientifica-2001/avaliacao-da-qualidademicrobiologica-da-agua-de-propriedades-leiteirasresultados-parcias>. Acesso em: 01 jun. 2010. 
RIBEIRO, A.R.; SILVA, J.A.B.; GARINO JUNIOR, F.; COSTA, E.O. Análise microbiológica da qualidade da água utilizada na ordenha em propriedades leiteiras do Estado de São Paulo e Minas Gerais. Napgama, São Paulo, v.3, n.3, p.3-6, 2000.

SÁ, L. L. C.; JESUS, I. M.; SANTOS, E. C. O.; VALE, E.R.; LOUREIRO, E.C.B.; SÁ, E.V. Qualidade microbiológica da água para consumo humano em duas áreas contempladas com intervenções de saneamento - Belém do Pará, Brasil. Epidemiologia e Serviços de Saúde, Brasília, vol. 14, n. 3, p. 171-180, 2005.

SANTOS, M. V.; FONSECA, L. F. L. Estratégias para Controle de Mastite e Melhoria da Qualidade do Leite. Barueri: Editora Manole Ltda, 2007. 314p.

SANTOS, M. V.; FONSECA, L. F. L. Curso online: Monitoramento da qualidade do leite - Módulo 2: qualidade microbiológica do leite: métodos de análise e estratégias de controle. Disponível em: <http:// paraiso.ifto.edu.br/docente/admin/upload/docs_upload/ material_26df0a43b5.pdf>. Acesso em: 19 abr. 2009.

SCALCO, A. R.; TOLEDO, J. C. Modelo de referência para gestão da qualidade na cadeia de produção de leite e derivados. 2005. Tese (Doutorado em Engenharia de Produção). Universidade Federal de São Carlos, São Carlos.

WHO: World Health Organization; UN-WATER. GLAAS 2010. UN-Water Global Annual Assessment of Sanitation and Drinking Water: targeting resources for better results. Geneva: WHO, UN-Water, 2010. 